\title{
Characteristics and sources of polycyclic aromatic hydrocarbons in atmospheric aerosols in the Kathmandu Valley, Nepal
}

\author{
Pengfei Chen ${ }^{\text {a,e }}$, Shichang Kang b,c , Chaoliu Li a,*, Maheswar Rupakheti ${ }^{\text {d, }}$ Fangping Yan ${ }^{\text {b,e }}$, Quanlian Li ${ }^{\text {b }}$, \\ Zhenming Ji ${ }^{\mathrm{a}}$, Qianggong Zhang ${ }^{\mathrm{a}, \mathrm{c}}$, Wei Luo ${ }^{\mathrm{f}}$, Mika Sillanpää ${ }^{\mathrm{g}}$ \\ ${ }^{a}$ Key Laboratory of Tibetan Environment Changes and Land Surface Processes, Institute of Tibetan Plateau Research, Chinese Academy of Sciences, Beijing 100101, China \\ b State Key Laboratory of Cryospheric Science, Cold and Arid Regions Environmental and Engineering Research Institute, Chinese Academy of Sciences, Lanzhou 730000, China \\ c Center for Excellence in Tibetan Plateau Earth Sciences, Chinese Academy of Sciences, Beijing 100085, China \\ ' Institute for Advanced Sustainability Studies, Potsdam 14467, Germany \\ e Graduate University of Chinese Academy of Sciences, Beijing 100039, China \\ ${ }^{f}$ State Key Lab of Urban and Regional Ecology, Research Center for Eco-Environmental Sciences, Chinese Academy of Sciences, Beijing 100085, China \\ ${ }^{g}$ Laboratory of Green Chemistry, Lappeenranta University of Technology, Sammonkatu 12, 50130 Mikkeli, Finland
}

\section{H I G H L I G H T S}

- High concentrations of 4-6 ring PAHs were reported in the atmosphere of Kathmandu.

- PAH concentrations in non-monsoon season were higher than those in monsoon season.

- PAH ratios indicated that diesel and biomass fuels were main emission sources.

- Toxic equivalent concentration of PAHs was 26 times higher than the WHO guideline.
G R A P H I C A L A B S T R A C T

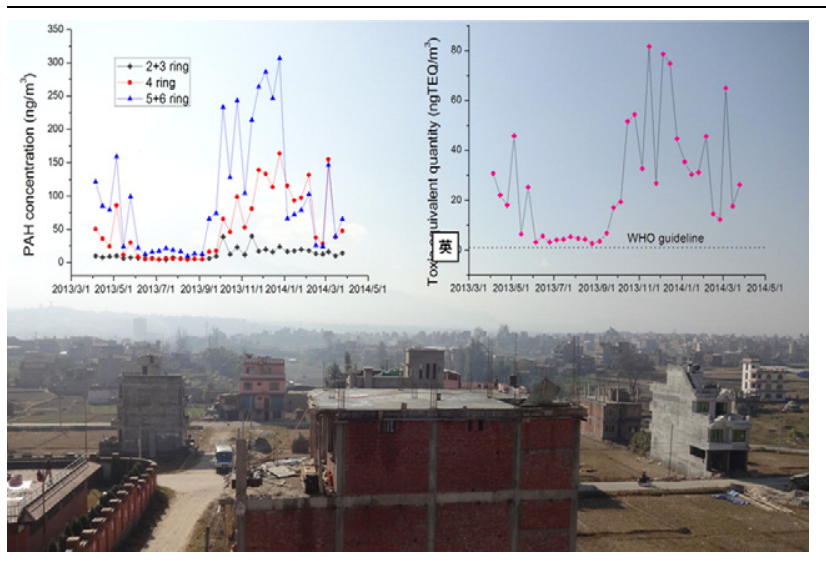

\section{A B S T R A C T}

The Kathmandu Valley in the foothills of the Himalayas, where the capital city of Nepal is located, has one of the most serious air pollution problems in the world. In this study, total suspended particle (TSP) samples collected over a year (April 2013-March 2014) in the Kathmandu Valley were analyzed for determining the concentrations of 15 priority particle-bound polycyclic aromatic hydrocarbons (PAHs). The TSP and PAH concentrations were extremely high, with annual average concentration being $199 \pm 124 \mu \mathrm{g} / \mathrm{m}^{3}$ and $155 \pm 130 \mathrm{ng} / \mathrm{m}^{3}$, respectively, which are comparable to those observed in Asian cities such as Beijing and Delhi. The TSP and PAH concentrations varied considerably, with the seasonal average concentration being maximal during the post-monsoon season followed by, in descending order, the winter, pre-monsoon, and monsoon seasons. In the winter and premonsoon seasons, ambient TSP and PAH concentrations increased because of emissions from brick kilns and the use of numerous small generators. Moreover, in the pre-monsoon season, forest fires in the surrounding regions influenced the TSP and PAH concentrations in the valley. PAHs with 4 to 6 rings constituted a predominant proportion (92.3-93.3\%) of the total PAHs throughout the year. Evaluation of diagnostic molecular ratios indicated that the atmospheric PAHs in the Kathmandu Valley originated mainly from diesel and biomass

\section{Keywords:}

Polycyclic aromatic hydrocarbons

Total suspended particles

Source

Health risk

Kathmandu

\footnotetext{
* Corresponding author at: Key Laboratory of Tibetan Environment Changes and Land Surface Processes, Institute of Tibetan Plateau Research, Chinese Academy of Sciences, Lin Cui Road, Chaoyang District, Beijing, 100101, China.
}

E-mail address: lichaoliu@itpcas.ac.cn (C. Li). 
combustion. The toxic equivalent quantity (TEQ) of particle phase PAHs ranged between 2.74 and $81.5 \mathrm{ng}$ TEQ/ $\mathrm{m}^{3}$, which is considerably higher than those reported in other South Asian cities, and 2-80 times higher than the World Health Organization guideline $\left(1 \mathrm{ng} \mathrm{TEQ} / \mathrm{m}^{3}\right)$. This suggests that ambient PAH levels in the Kathmandu Valley pose a serious health risk to its approximately 3.5 million residents.

(c) 2015 Elsevier B.V. All rights reserved.

\section{Introduction}

Polycyclic aromatic hydrocarbons (PAHs), a large group of organic compounds with two or more aromatic rings, are generated through incomplete combustion of organic materials such as coal, oil, gas, waste and biomass (Nielsen et al., 1996; Singh et al., 2013; Zhang and Tao, 2009). Such compounds pose serious health concerns in both developed and developing countries because of their carcinogenic, mutagenic and teratogenic properties (Bhargava et al., 2004). In general, PAHs exist in the atmosphere in both gas and particle phases (Wang et al., 2013) and are hazardous to humans when inhaled (Gong et al., 2011; Sharma et al., 2007). Certain PAHs and their ratios have been used as markers for determining their various contributing sources (Kulkarni and Venkataraman, 2000; Liu et al., 2013; Rajput and Lakhani, 2009). Because PAHs are persistent in the atmosphere, they can be transported over long distances, even to remote areas such as the Arctic and the Himalayas (Crimmins et al., 2004; Ding et al., 2007).

The region encompassing the Himalayan Mountains and their foothills is one of the least scientifically studied regions in the world regarding the emissions, concentrations, transport, transformation, removal, and effects of various air pollutants, including PAHs. Anthropogenic emissions within the mountain region are not major compared with those in the upwind adjacent regions of South Asia such as the populous, rapidly developing, and highly polluted Indo-Gangetic Plain (IGP), which is a major regional or global source of organic pollutants in the atmosphere (Singh et al., 2013; Zhang and Tao, 2009). For example, Delhi and Kanpur, two large cities in the IGP, exhibited extremely high PAH concentrations, with annual mean values of the sum of several PAHs being 850 and $660 \mathrm{ng} / \mathrm{m}^{3}$, respectively (Masih et al., 2010; NEERI, 2006). Asian monsoon circulation and westerly winds distribute and transport anthropogenic and natural air pollutants in the Himalayan region (Ming et al., 2008). The unique meteorological characteristics of the region, including a long (NovemberMay) dry season, are conducive to the accumulation of air pollutants, notably on the southern flank of the Himalayan Mountains (Ramanathan et al., 2007). Therefore, the anthropogenic emissions of various pollutants, including PAHs, upwind of and within the Himalayan region are a threat to both public health and local ecosystems. However, the basic information available on the characteristics of atmospheric PAHs in this region (sources, types, emissions, concentrations, and fate) remains limited.

The Kathmandu Valley, in which the capital city of Nepal, Kathmandu, is located, is the largest metropolitan area in the Himalayan foothills (Fig. 1), and is characterized by rapid but uncontrolled urban growth (Panday and Prinn, 2009; Sharma, 1997; Shrestha and Malla, 1996). The Kathmandu Valley is shaped like a circular bowl with a $630 \mathrm{~km}^{2}$ watershed and $340-\mathrm{km}^{2}$ flat floors at approximately $1300 \mathrm{~m}$ above mean sea level surrounded by a rim of hills $500-3000 \mathrm{~m}$ above the valley floor. The valley comprises nearly 3.5 million residents and has a severe air pollution problem (Aryal et al., 2008; Kando et al., 2005; Gurung and Bell, 2013). Only one study examined ambient PAHs in this region, and it reported extremely high total PAH concentrations $\left(640 \mathrm{ng} / \mathrm{m}^{3}\right)$ in Kathmandu in winter (Kishida et al., 2009). The present study presents results of year-long measurement of 15 priority particle phase PAHs in the Kathmandu Valley. To our knowledge, this is the first report of the seasonal characteristics of ambient particle-bound PAH concentrations in the Kathmandu Valley and the surrounding broader Himalayan foothills. The main objectives of this study were to: (1) investigate the total suspended particle (TSP) and PAH concentrations in the atmosphere of Kathmandu and compare the data with those in other regions, (2) assess the seasonal variations of TSP and PAH concentrations and identify the sources of these pollutants, and (3) assess the health risk that PAH exposure imposes on the local residents.

\section{Sampling and analysis}

\subsection{Sampling site and TSP sample collection}

TSP sampling was conducted at Bode $\left(27.69^{\circ} \mathrm{N}, 85.40^{\circ} \mathrm{E}\right)$ in Bhaktapur, which is located at nearly the center of the Kathmandu Valley. The measurement site is in a mixed agricultural-residential area. Approximately 10 highly polluting brick kilns are located within a 2-km radius of the site, and are in operation from January to April every year. The wind direction through the valley is usually southwesterly or westerly, with relatively low speeds in the range of $0.5-7.5 \mathrm{~m} / \mathrm{s}$ (Giri et al., 2006; Shrestha and Aryal, 2011). Therefore, the site receives urban air pollution from three major cities in the valley, namely Kathmandu, Lalitpur, and Bhaktapur, located to the west, southwest, and southeast of the site, respectively. It also receives regional air masses mainly from the south. South Asian monsoon circulations influence the weather in Nepal, which is characterized by four distinct seasons: winter (December-February), pre-monsoon (MarchMay), monsoon (June-September), and post-monsoon (October-November) seasons (Bonasoni et al., 2010). The summer monsoon season is hot, humid, and rainy, with nearly $80 \%$ of the annual precipitation of $1400 \mathrm{~mm}$ occurring in 4 months (Giri et al., 2006). The post-monsoon season is warm and sunny. The winter and pre-monsoon seasons are relatively dry with only a few rain events caused by westerly weather systems. The ambient air temperature in the Kathmandu Valley may reach $35^{\circ} \mathrm{C}$ in summer (monsoon season), whereas that in winter (from December to January) is approximately $0{ }^{\circ} \mathrm{C}$.

For sampling, a TSP filter sampler was placed on the rooftop (15 m above ground) of a residential building. Fifty TSP samples were collected on pre-baked quartz fiber filters (90-mm diameter, Whatman plc, Maidstone, UK) by using a filter sampler fitted with a TSP cyclone (flow rate: 100 L/min, KC-120H: Qingdao Laoshan Applied Technology Institute, Qingdao City, China). Each sample was collected for 24 h every 8 days to avoid the weekend effect. Field blank filters were placed in the sampler without air being drawn through it. The quartz fiber filters were pre-treated by baking them at $550{ }^{\circ} \mathrm{C}$ for at least $6 \mathrm{~h}$ to reduce residual organic matter. The pre- and post-sampling weights of all quartz filters were determined using a microbalance after it was equilibrated at a constant temperature and humidity $\left(20^{\circ} \mathrm{C}, 39 \%\right)$ for at least $24 \mathrm{~h}$. The samples were stored at $4{ }^{\circ} \mathrm{C}$ before extraction and chemical analysis. The volume of air passing through each filter was converted into standard atmospheric conditions $\left(25^{\circ} \mathrm{C}, 1000 \mathrm{mb}\right)$ by using the atmospheric pressure and ambient temperature monitored at the site.

\subsection{Extraction and analysis}

Wang et al. (2013) detailed the procedure used for extracting and analyzing TSP filter samples. This paper briefly describes the method. A quarter of each filter was cut into pieces, placed in a glass tube, and immersed in $20 \mathrm{~mL}$ of dichloromethane (DCM) and $n$-hexane (1:1). Extraction was conducted by applying a sonication process twice at $27{ }^{\circ} \mathrm{C}$ for $30 \mathrm{~min}$. Every sample was spiked with deuterated PAHs (naphthalene-d8, acenaphthene-d10, phenanthrene-d10, chrysene$\mathrm{d} 12$, and perylene-d12) as recovery surrogates. The extracts were evaporated to approximately $0.5 \mathrm{~mL}$ by using a rotary evaporator and were 


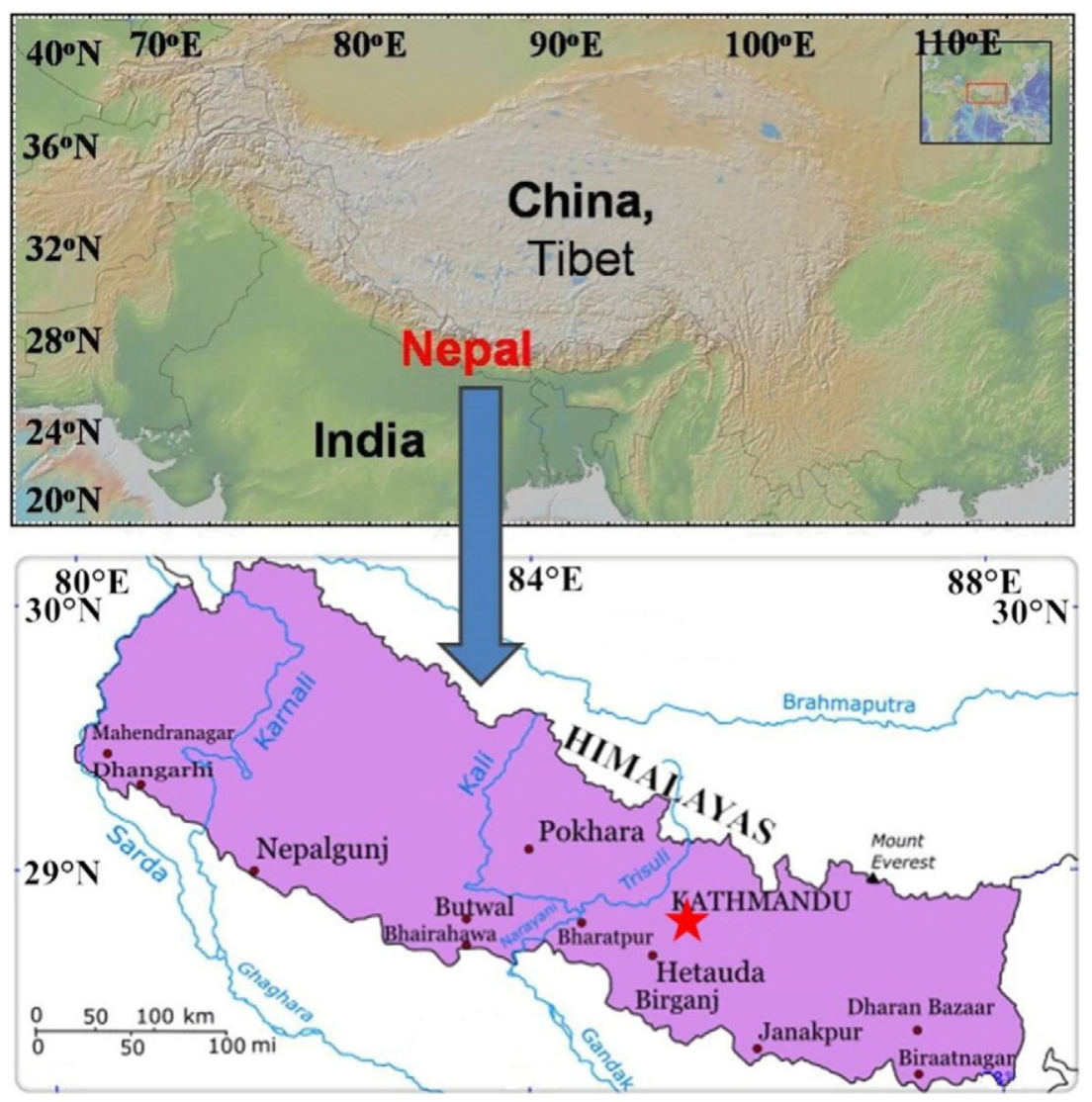

Fig. 1. Location of the Kathmandu Valley, Nepal.

transferred to a multilayer column filled with $2 \mathrm{~g}$ of activated silica gel, $4 \mathrm{~g}$ of neutral alumina, and $1 \mathrm{~cm}$ of anhydrous $\mathrm{Na}_{2} \mathrm{SO}_{4}$ (pre-soaked in $n$ hexane). Subsequently, the column was eluted using a mixture of $10 \mathrm{~mL}$ of $n$-hexane and $20 \mathrm{~mL}$ of DCM $/ n$-hexane (1:1). The eluent solvent was blown down to a final volume of $1 \mathrm{~mL}$ under a gentle stream of nitrogen. Finally, the solution was transferred to a $1.5-\mathrm{mL}$ vial and stored at $-20{ }^{\circ} \mathrm{C}$ for rejection.

The PAHs were analyzed at the State Key Laboratory of Cryospheric Sciences, Cold and Arid Regions Environmental and Engineering Research Institute in China by using gas chromatography-mass spectrometry with a $30 \times 250-\mu \mathrm{m}$ ID HP-5MS capillary column according to a method described by Gong et al. (2011). High-purity helium was used as a carrier gas at a constant flow rate of $1.0 \mathrm{~mL} / \mathrm{min}$. The mass spectrometer was operated in 70-eV electron impact mode. The oven temperature was $100^{\circ} \mathrm{C}$, which was maintained for $2 \mathrm{~min}$. subsequently, it was increased to the final temperature of $260{ }^{\circ} \mathrm{C}$ at various rates; specifically, it was increased to $170^{\circ} \mathrm{C}$ at $25^{\circ} \mathrm{C} / \mathrm{min}, 225^{\circ} \mathrm{C}$ at $8{ }^{\circ} \mathrm{C} / \mathrm{min}$, $235^{\circ} \mathrm{C}$ at $0.7{ }^{\circ} \mathrm{C} / \mathrm{min}$, and $260{ }^{\circ} \mathrm{C}$ at $25^{\circ} \mathrm{C} / \mathrm{min}$, and finally maintained at $260^{\circ} \mathrm{C}$ for $2 \mathrm{~min}$. The temperature of the injector was $250{ }^{\circ} \mathrm{C}$ and that of the transfer line was $280^{\circ} \mathrm{C}$. Samples were analyzed for the 15 PAHs listed by the U.S. Environmental Protection Agency as priority PAHs: acenaphthene (Ace), acenaphthylene (Aecl), anthracene (Ant), fluorine (Flu), phenanthrene (Phe), benzo(a)anthracene (BaA), chrysene (Chr), fluoranthene (Fla), pyrene (Pyr), benzo(a)pyrene $(\mathrm{BaP})$, benzo(b)fluoranthene $(\mathrm{BbF})$, benzo(k)fluoranthene $(\mathrm{BkF})$, dibenzo(a,h)anthracene (DahA), benzo(g,h,i)perylene (BghiP) and indeno( $1,2,3-\mathrm{cd})$ pyrene (IndP). A small pouch $\left(0.5025 \mathrm{~cm}^{2}\right)$ of filter sample was prepared to analyze organic carbon (OC) and elemental carbon (EC) by Desert Research Institute (DRI) Model 2001 Thermal/ Optical Carbon Analyzer (Atmoslytic Inc., Calabasas, CA, USA) (Cao et al., 2005).

\subsection{Quality control}

All analytical procedures were conducted using strict quality assurance and control measures. Laboratory blanks for air samples were included at a rate of one for every five samples and were treated in exactly the same manner as the samples. The field blanks for the air samples were extracted and analyzed using the same method used for the samples. Method detection limits (MDLs) were derived as 3 times the standard deviation of the mean blank concentrations. However, most of the PAHs, apart from Nap were not detected in the laboratory and field blanks, indicating that the contamination of most PAHs was negligible during transportation, storage, and analysis. Therefore, we did not analyze the Nap component. The detection limits were 0.84 (Acel), 0.59 (Ace), 0.70 (Phe), 0.39 (Ant), 0.06 (Flu, Fla, Bbf, DahA, and BghiP) and $0.03 \mathrm{pg} / \mathrm{m}^{3}$ (Pyr, BaA, Chr, Bkf, BaP, and IndP). The recoveries in the field samples were $75-108 \%, 82-112 \%, 83-114 \%, 88-126 \%$, and 89-123\% for naphthalene-d8, acenaphthene-d10, phenanthrene-d10, chrysene-d12, and perylene-d12 as inferred standards, respectively. The PAH concentrations were blank corrected but not corrected for the recoveries.

\subsection{Gas/particle partitioning estimation}

Octanol-air partition coefficient $\left(\mathrm{K}_{\mathrm{OA}}\right)$-based model has been proved applicable to estimate the gas-particle partitioning of PAHs (Ma et al., 2011; Wang et al., 2011). The temperature-dependent $\mathrm{K}_{\mathrm{OA}}$ values can be measured directly using the GC retention time method with an equation as Eq. (1) (Harner and Bidleman, 1996):

$\log \mathrm{K}_{\mathrm{OA}}=\mathrm{A}+\mathrm{B} /(\mathrm{T}, \mathrm{K})$ 
The regression parameters (A and B) (Table SI-1) were given by Harner and Bidleman (1998) and Odabasi et al. (2006). The difference of $\mathrm{K}_{\mathrm{OA}}$ values of PAHs among four seasons were calculated by adjusting the equations to the average ambient temperature (Pre-monsoon: $20{ }^{\circ} \mathrm{C}$, Monsoon: $24{ }^{\circ} \mathrm{C}$, Post-monsoon: $18{ }^{\circ} \mathrm{C}$, and Winter: $11^{\circ} \mathrm{C}$ ). Then the gas-particle partition coefficient $\left(\mathrm{K}_{\mathrm{P}}\right)$ can be predicted by Eq. (2) if the organic matter fraction fom of the aerosols are known and assuming that all of the particle organic matter is available to absorb gas-phase compounds.

$\log \mathrm{K}_{\mathrm{P}}=\log \mathrm{K}_{\mathrm{OA}}+\log$ fom-11.91

In this study, the average organic carbon concentrations were 63.1, $15.3,31.8$, and $66.8 \mu \mathrm{g} / \mathrm{m}^{3}$ for these four seasons in aerosols of sampling site. Transformation of these values into organic matter leads to $24 \%$, $18 \%, 20 \%$, and $24 \%$, respectively. Finally, we can estimate the gas phase PAHs using Eq. (3):

$K_{\mathrm{P}}=\left(\mathrm{C}_{\mathrm{p}} / \mathrm{C}_{\mathrm{TSP}}\right) / \mathrm{C}_{\mathrm{g}}$

where $C_{p}$ and $C_{g}$ are the PAH concentrations in the particle and gas phases, respectively, and $C_{\text {TSP }}$ is the concentration of TSP in the air.

\subsection{Toxic equivalent quantity estimation}

The toxic equivalent quantity (TEQ) was assessed using the toxic equivalency factors (TEFs) provided by Nisbet and LaGoy (1992). As shown in Table 3, the TEQ in different seasons was calculated using the following formula:

$\mathrm{TEQ}=\Sigma \mathrm{i}(\mathrm{Ci} \times \mathrm{TEFi})$

where $\mathrm{Ci}$ is the concentration of an individual PAH, TEFi is the toxic equivalent factor, and TEQ is the toxic equivalent of the reference compound.

\section{Results and discussion}

\subsection{TSP and PAH concentrations}

Table 1 shows a summary of the ambient TSP and PAH concentrations. During the study period, the annual average TSP and PAH concentrations were similar to those reported in numerous other Asian cities, such as Delhi (Sarkar and Khillare, 2013) and Agra (Rajput and Lakhani, 2010) in India and Beijing in China (Okuda et al., 2006), but were significantly higher than those observed at sites in Asia such as Lhasa in China (Gong et al., 2011) and Sihwa in Korea (Park et al., 2011). The PAH concentrations ranged between 18.1 and $453 \mathrm{ng} / \mathrm{m}^{3}$, indicating that both the PAH and TSP concentrations fluctuated over wide ranges during the sampling period. Although the total mass of 15 particle-bound PAHs constituted only a small fraction $(0.08 \%)$ of the TSP composition, the monthly averages of the total PAH and TSP concentrations were positively correlated $\left(r^{2}=0.63 ; p<0.05\right)$.

The high ambient PAH concentrations in the Kathmandu Valley pose serious health and environmental concerns. Previous studies on particulate chemical composition, including carbonaceous aerosols, ions/ metals, and PAHs, have suggested that the atmospheric composition in the Kathmandu Valley is considerably influenced by anthropogenic emissions from sources such as vehicles, industries, and biomass burning, and even the long-range transportation of pollutants from the Indian subcontinent (Kishida et al., 2009; Shakya et al., 2010; Tripathee et al., 2014).

\subsection{Seasonal variations of TSP and PAH concentrations}

The TSP and total PAH concentrations demonstrated clear seasonal variation (Fig. 2), with concentrations being high in the pre-monsoon season, gradually decreasing to minimum concentrations around the mid-monsoon season, and then increasing through the post-monsoon season to maximum concentrations in the early winter. Kishida et al. (2009) described a similar seasonal trend in particle phase PAHs (in $\mathrm{PM}_{10}$ ). Various sources of suspended particles and PAHs exist in the Kathmandu Valley. Nepal experiences acute power shortages throughout the year, particularly during the winter and pre-monsoon season. Daily power cuts can last for 10-18 h. This has resulted in the using of nearly 250,000 small generators, mainly diesel powered, in the Kathmandu Valley alone, causing particulate matter and PAH emissions. Nearly 120 polluting brick kilns, operated from January to April every year, exist in the valley, and low-quality coal is mostly used in these kilns (Kishida et al., 2009; Central Bureau of Statistics, 2006). Furthermore, approximately 700,000 vehicles are in the valley, constituting

Table 1

Summary of TSP concentrations $\left(\mu \mathrm{g} / \mathrm{m}^{3}\right)$ and particle-bound PAH concentrations $\left(\mathrm{ng} / \mathrm{m}^{3}\right)$ in the Kathmandu Valley and other regions.

\begin{tabular}{|c|c|c|c|c|c|c|c|c|c|}
\hline SN & $\mathrm{PAH}$ & Ring & Mean (SD) & Minimum & 25th & 75th & Maximum & $\%$ of $\Sigma \mathrm{PAHs}$ & Reference \\
\hline 1 & Ace & 3 & $0.822(0.464)$ & 0.401 & 0.524 & 0.870 & 2.88 & 0.530 & This study \\
\hline 2 & Acel & 3 & $0.590(0.221)$ & 0.360 & 0.425 & 0.701 & 1.32 & 0.382 & This study \\
\hline 3 & Ant & 3 & $1.20(0.494)$ & 0.684 & 0.780 & 1.03 & 2.82 & 0.771 & This study \\
\hline 4 & Flu & 3 & $1.64(1.18)$ & 0.762 & 0.983 & 1.23 & 5.66 & 1.13 & This study \\
\hline 5 & Phe & 3 & $4.48(4.02)$ & 0.360 & 1.45 & 2.82 & 17.3 & 2.90 & This study \\
\hline 6 & $\mathrm{BaA}$ & 4 & $11.8(11.6)$ & 0.872 & 1.18 & 7.53 & 38.5 & 7.51 & This study \\
\hline 7 & Chr & 4 & $13.8(13.2)$ & 1.16 & 1.69 & 9.32 & 45.9 & 8.92 & This study \\
\hline 8 & Fla & 4 & $11.7(11.2)$ & 1.02 & 1.50 & 7.71 & 36.9 & 7.51 & This study \\
\hline 9 & Pyr & 4 & $12.1(11.3)$ & 1.12 & 1.71 & 8.14 & 42.9 & 7.80 & This study \\
\hline 10 & $\mathrm{BaP}$ & 5 & $16.6(15.2)$ & 1.12 & 2.49 & 12.1 & 54.6 & 10.7 & This study \\
\hline 11 & $\mathrm{BbF}$ & 5 & $17.7(15.8)$ & 1.62 & 2.85 & 13.2 & 58.7 & 11.4 & This study \\
\hline 12 & $\mathrm{BkF}$ & 5 & $17.3(15.1)$ & 1.83 & 2.75 & 13.9 & 50.5 & 11.1 & This study \\
\hline 13 & DahA & 5 & $2.03(1.80)$ & 0.580 & 0.800 & 0.970 & 8.09 & 1.30 & This study \\
\hline 14 & BghiP & 6 & $20.7(18.7)$ & 2.04 & 4.95 & 21.0 & 95.4 & 13.4 & This study \\
\hline \multirow[t]{8}{*}{15} & IndP & 6 & $22.6(20.6)$ & 2.05 & 5.22 & 20.9 & 91.3 & 14.6 & This study \\
\hline & Total PAHs & & $155(130)$ & 18.1 & 31.5 & 239 & 453 & 100 & This study \\
\hline & TSP & & $199(124)$ & 32.0 & 95.7 & 287 & 555 & & This study \\
\hline & Delhi $^{\mathrm{a}}$ & $\mathrm{PM}_{10}$ & 105 & 11.0 & & & 512 & & Sarkar and Khillare (2013) \\
\hline & Agrab $^{\mathrm{b}}$ & TSP & 120 & 15.0 & & & 392 & & Rajput and Lakhani (2010) \\
\hline & Lhasa $^{\mathrm{c}}$ & TSP & $35.7(15.9)$ & 11.4 & & & 72.5 & & Gong et al. (2011) \\
\hline & Beijing $^{d}$ & TSP & 160 & & & & - & & Okuda et al. (2006) \\
\hline & Sihwa ${ }^{\mathrm{e}}$ & TSP & $22.0(30.0)$ & 1.90 & & & 128 & & Park et al. (2011) \\
\hline
\end{tabular}

Superscripts a,b,c, e: 16 PAHs; superscript d: 12 PAHs. 


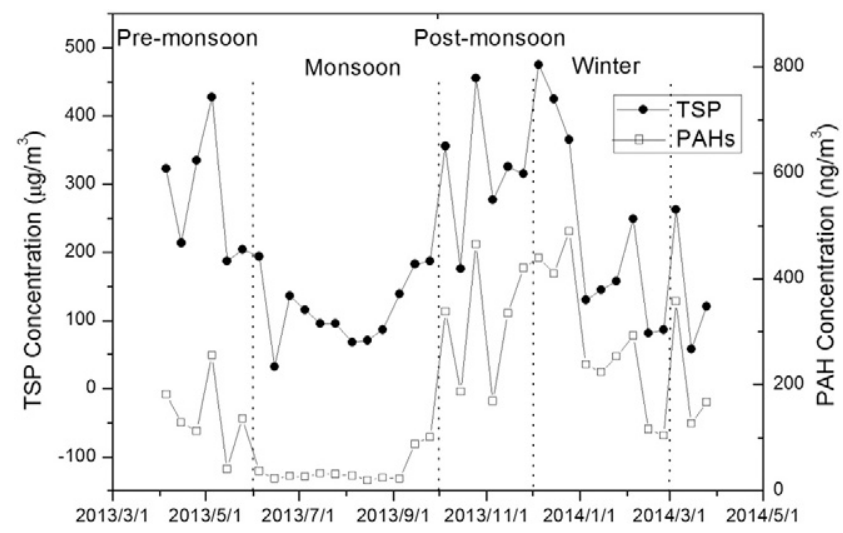

Fig. 2. Seasonal variations of TSP and PAH concentrations in the Kathmandu Valley.

almost half of the total number of vehicles in the country. Garbage burning is another apparent and major source of air pollution. Biomass, such as wood, agricultural waste, and cattle dung, is burnt almost throughout the year mainly for cooking. A considerable amount of agro-residue is also burned in northern India and southern Nepal (Ram and Sarin, 2010). These activities emit high quantities of PAHs and other air pollutants (Sinha et al., 2014). Furthermore, forest fires increase considerably in the pre-monsoon season in the region (Vadrevu et al., 2012). In addition, the westerly winds during the winter and pre-monsoon seasons create relatively dry and cold conditions. The unique weather conditions of the region (long dry season extending from November to May), combined with its geophysical features create an environment conducive to the accumulation of air pollutants outside the monsoon season, often leading to the formation of air pollutant plumes on a regional scale, called atmospheric brown clouds; this results in high pollutant concentrations on the southern side of the Himalayas (Ram et al., 2012; Rengarajan et al., 2007). Furthermore, the ambient temperature considerably affects the gas-particle partitioning of PAHs (Sitaras et al., 2004; Tham et al., 2008). Usually, high temperatures enhance the evaporation of particle phase PAHs to gas phases, whereas low temperatures strengthen the condensation of gas phase PAHs onto atmospheric particles, leading to higher concentrations of particle-phase PAHs in the winter and lower concentrations in the summer. The $\mathrm{K}_{\mathrm{OA}}$-based absorption model was applied to estimate the gas-particle partitioning of PAHs. The result shows that the gas phase concentrations of low molecular weight PAHs (Ace, Aecl, Ant, Flu, and Phe) revealed clear seasonal variation with approximately 1 times higher concentrations in the monsoon and post-monsoon seasons than those in winter and pre-monsoon season, while other PAH species were almost in the same order all the year around. This means that the temperature was an important factor which could lead to the seasonal variation of PAH concentrations. However, the difference for particle phase PAHs among these four seasons could be as large as 4 times, suggesting that the shift in gas-particle partitioning was not the prime reason. Thus, we believe that the observed seasonality was mainly caused by change of emission sources. Other factors, including diminished atmospheric dispersion caused by lower atmospheric mixing levels and decreased photochemical oxidation in winter, may also contribute to high wintertime PAH concentrations (Table 2).

The increase in TSP and PAH concentrations in the post-monsoon season is attributable to the rise in agro-residue burning in the regions surrounding the Kathmandu Valley; moreover, that in the winter and pre-monsoon seasons is due to emissions from additional sources such as brick kilns, increased use of biomass for cooking and heating when the temperature drops to approximately $0{ }^{\circ} \mathrm{C}$ in winter months, and high consumption of diesel and petrol in the small but numerous generators across the Kathmandu Valley. By contrast, high rainfall
Table 2

Seasonal mean TSP $\left(\mu \mathrm{g} / \mathrm{m}^{3}\right)$ and PAH concentrations $\left(\mathrm{ng} / \mathrm{m}^{3}\right)$ in the four seasons in the Kathmandu Valley. The number in parenthesis represents the percentage contribution (\%) of individual PAH to the total PAH concentration in each season.

\begin{tabular}{llllll}
\hline SN & PAH & Pre-monsoon & Monsoon & Post-monsoon & Winter \\
\hline 1 & Ace & $0.820(0.624)$ & $0.714(1.21)$ & $1.110(0.421)$ & $0.810(0.322)$ \\
2 & Acel & $0.505(0.312)$ & $0.507(0.812)$ & $0.882(0.307)$ & $0.700(0.304)$ \\
3 & Ant & $1.05(0.707)$ & $0.941(1.63)$ & $1.58(0.524)$ & $1.55(0.638)$ \\
4 & Flu & $1.07(0.721)$ & $1.58(2.61)$ & $2.91(0.901)$ & $1.70(0.725)$ \\
5 & Phe & $3.11(2.11)$ & $2.51(4.22)$ & $8.51(2.73)$ & $6.92(2.917)$ \\
6 & BaA & $9.74(6.70)$ & $2.86(4.81)$ & $20.8(6.60)$ & $23.2(9.73)$ \\
7 & Chr & $12.9(9.04)$ & $3.17(5.30)$ & $22.9(7.31)$ & $26.3(11.3)$ \\
8 & Fla & $10.4(7.20)$ & $3.17(5.34)$ & $17.6(5.62)$ & $23.3(9.71)$ \\
9 & Pyr & $11.4(7.82)$ & $3.53(5.91)$ & $19.2(6.13)$ & $22.4(9.42)$ \\
10 & BaP & $15.5(10.7)$ & $5.73(9.53)$ & $34.7(11.2)$ & $23.9(10.1)$ \\
11 & BbF & $16.4(11.3)$ & $6.32(10.5)$ & $38.1(12.1)$ & $24.7(10.3)$ \\
12 & BkF & $17.4(12.0)$ & $6.27(10.4)$ & $33.3(10.5)$ & $24.4(10.2)$ \\
13 & DahA & $1.89(1.30)$ & $1.32(2.20)$ & $4.60(1.5)$ & $1.69(0.74)$ \\
14 & BghiP & $18.8(12.9)$ & $9.43(15.7)$ & $49.4(15.6)$ & $25.2(10.6)$ \\
15 & IndP & $20.9(14.4)$ & $9.72(16.2)$ & $54.6(17.3)$ & $26.9(11.3)$ \\
& Total PAHs & $141(100)$ & $57.7(100)$ & $310(100)$ & $234(100)$ \\
& TSP & 353 & 116 & 225 & 362 \\
\hline
\end{tabular}

during the monsoon season (almost $80 \%$ of the total annual precipitation) washes suspended particles and PAHs from the atmosphere and increased temperatures raises the evaporation of particle phase PAHs. Thus, the seasonal distribution of TSP and PAHs in the Kathmandu Valley is controlled by multiple factors: emissions, temperature, dispersion conditions, rainfall, and chemical mechanisms (Caricchia et al., 1999).

\subsection{PAH compositions}

The mentioned 15 particle phase PAHs were classified into the following 4 groups according to the number of aromatic rings (Kaur et al., 2013): 3-ring (Acel, Ace, Flu, Phe, and Ant), 4-ring (Fla, Pry, BaA, and $\mathrm{Chr}$ ), 5-ring (BbF, BkF, BaP, and DahA), and 6-ring (IndP and BghiP) PAHs. Fig. SI-1 shows the relative proportions of individual PAHs among the total atmospheric PAHs in the Kathmandu Valley in the four seasons. Although certain differences in the distribution patterns of the PAHs were noticeable at various sampling periods, the 4-, 5-, and 6-ring PAHs (92.3-93.3\%) constituted the predominant proportion of the PAHs in each season. This result is consistent with those of a previous report on Kathmandu (Kishida et al., 2009).

The 4-ring PAHs constituted a relatively high proportion of the total PAHs in the post-monsoon (41.0\%) and winter (33.8\%) seasons, and accounted for $25.2 \%$ and $22.0 \%$ of the total PAHs in the pre-monsoon and monsoon seasons. Accordingly, the proportion of the 3-ring PAHs slightly decreased to $4.59 \%$ and $5.65 \%$ in the post-monsoon and winter seasons (Table SI-2). As mentioned above, temperature exerts a major influence on the gas-particle partitioning of PAHs. Thus, the seasonal variation of the 3- and 4-ring PAHs may be related to the temperature fluctuation.

\subsection{Identification of PAH sources}

Because different combustion types emit different mixtures of PAHs, some PAHs can be used as indicators of burning history or potential source of emissions. Parent PAH ratios are frequently used to identify the origin of PAHs (Rajput et al., 2014; Yunker et al., 2002). In general, various ratios are used simultaneously to cross-check the results and reduce uncertainties. In the present study, the concentration ratios IndP / (IndP + BghiP), Fla / (Fla + Pyr), BaA / (BaA + Chr) and BghiP/BaP of the particle phase PAHs were used as indicators for investigating emission sources, and Table SI-3 shows the results. The IndP / (IndP + BghiP) values were higher than 0.5 in all seasons, indicating a strong 
Table 3

Toxic equivalent quantity (TEQ) values of particle phase PAHs in the Kathmandu Valley and Asian cities.

\begin{tabular}{llcll}
\hline City & PM & $\begin{array}{l}\text { TEQ } \\
\left(\mathrm{ng} \mathrm{TEQ} / \mathrm{m}^{3}\right)\end{array}$ & Period & Reference \\
\hline Agra, India & $\mathrm{PM}_{10}$ & 7.8 & $2005-2006$ & Masih et al. (2010) \\
Mengmai, India & $\mathrm{TSP}^{2}$ & 8.9 & 2006 & Cheng et al. (2013) \\
Dongying, China & $\mathrm{TSP}$ & 1.84 & 2011 & Zhu et al. (2014) \\
Beijing, China & $\mathrm{PM}_{10}$ & 11.9 & 2003 & Zhou et al. (2005) \\
Kathmandu, Nepal & $\mathrm{TSP}^{26.2}$ & Annual & This study \\
& & 24.2 & Pre-monsoon & \\
& & 4.51 & Monsoon & \\
& 40.5 & Post-monsoon & \\
& & 32.9 & Winter & \\
\hline
\end{tabular}

contribution from coal and biomass combustion. The mean Fla / $($ Fla + Pyr) values for the pre-monsoon, monsoon, post-monsoon, and winter seasons were $0.48,0.46,0.47$, and 0.50 , respectively. The values were similar to those recorded for particles from rice and wheat residue burning. The $\mathrm{BaA} /(\mathrm{BaA}+\mathrm{Chr})$ values for all seasons varied from 0.37 to 0.49 with an average value of 0.45 , indicating that the PAHs were possibly of pyrolytic origin. The BaP/BghiP value was higher than 1.2 and lower than 2.2, implying that diesel was the main source. All ratios were fairly constant among the seasons, and this is attributable to the natural variability in environmental conditions.

The presented ratios suggest that both fossil fuel burning and biomass fuel burning are major sources of atmospheric PAHs in Kathmandu. Previous studies on OC/EC ratios and $\delta^{13} \mathrm{C}$ values of aerosols in Kathmandu have also indicated that local vehicular emissions were a major source of pollutants (Shakya et al., 2010). In addition, $\mathrm{PM}_{10}$ emissions from vehicular activities and industrial sources in Kathmandu constituted approximately $62 \%$ and $17 \%$ of the total $\mathrm{PM}_{10}$ emissions, respectively (ICIMOD, 2007).

\subsection{TEQ of PAHs}

The TEQ values during the sampling period varied from 2.74 to $81.5 \mathrm{ng} \mathrm{TEQ} / \mathrm{m}^{3}$, with an average of $26.2 \mathrm{ng} \mathrm{TEQ} / \mathrm{m}^{3}$, which is considerably higher than the national standard of China (10 ng TEQ $/ \mathrm{m}^{3}$; MEPC, 1996) and the World Health Organization guideline (1 $\mathrm{ng} \mathrm{TEQ} / \mathrm{m}^{3}$ ). The peak TEQ values occurring in the winter and post-monsoon seasons were 7.29 and 8.98 times higher than that in the monsoon season (4.51 ng TEQ/ $\mathrm{m}^{3}$ ) (Table 3). The reason for this low value is that the frequent monsoon rains removed most of the suspended particles from the air. Table 3 shows a comparison of the derived TEQ values with those observed in previous studies. Although the level in the monsoon season was slightly lower, the average annual TEQ values were markedly higher than those of cities in India (Masih et al., 2010; Cheng et al., 2013) and China (Zhu et al., 2014; Zhou et al., 2005), indicating that the carcinogenic risk of atmospheric PAHs in Kathmandu is extremely high. Furthermore, PAHs are present in the atmosphere in both particle and gas phases. A previous study reported that particle phase PAHs constituted nearly $33 \%$ of the total PAHs in the atmosphere of Kathmandu (Kishida et al., 2009). Therefore, if the gas phase PAHs were considered, the TEQ of the total PAHs in Kathmandu may be higher. This accentuates the necessity for more detailed surveys of $\mathrm{PAH}$ pollution.

\section{Conclusion}

In this study, the TSP $\left(199 \pm 124 \mu \mathrm{g} / \mathrm{m}^{3}\right)$ and PAH $\left(155 \pm 130 \mathrm{ng} / \mathrm{m}^{3}\right)$ concentrations observed in Kathmandu were relatively high compared with those measured in other parts of Asia. Clear seasonal variations in PAH concentrations were observed, with maximum and minimum concentrations occurring in the winter and monsoon seasons, respectively. The high $\mathrm{PAH}$ concentrations in the non-monsoon season are attributable to increased fuel consumption coupled with meteorological conditions such as an atmospherically stable layer and low temperature. Moreover, the low PAH concentrations in the monsoon season are attributable to heavy precipitation and high temperature. The emission sources of atmospheric PAHs were estimated using diagnostic molecular ratios. The results revealed that atmospheric PAHs in Kathmandu originated mainly from the combustion of fossil fuels (including vehicle engine exhausts and coal combustion) and biomass fuels. The average TEQ of PAHs was $26.2 \mathrm{ng} \mathrm{TEQ} / \mathrm{m}^{3}$, indicating that the effect of PAHs on human health is substantial. In summary, Kathmandu experiences extremely high levels of air pollution because of urbanization. Therefore, additional detailed surveys of this phenomenon and its effects are required.

\section{Acknowledgments}

This study was supported by the Strategic Priority Research Program (B) of the Chinese Academy of Sciences (XDB03030504), the National Natural Science Foundation of China (41271015, 41225002, and 41171398), and the Academy of Finland (decision number 268170). The authors acknowledge Dr. Junming Guo and Dr. Xin Wan for collecting and packing the samples. Furthermore, Dr. Nannan Pang and the staff at the Kathmandu sampling site were of considerable help in this study.

\section{Appendix A. Supplementary data}

Supplementary data to this article can be found online at http://dx. doi.org/10.1016/j.scitotenv.2015.08.006.

\section{References}

Aryal, R., Lee, B., Karki, R., Gurung, A., Kandasamy, J., Pathak, B., Sharma, S., Giri, N., 2008. Seasonal $\mathrm{PM}_{10}$ dynamics in Kathmandu Valley. Atmos. Environ. 42, 8623-8633.

Bhargava, A., Khanna, R., Bhargava, S., Kumar, S., 2004. Exposure risk to carcinogenic PAHs in indoor-air during biomass combustion whilst cooking in rural India. Atmos. Environ. 38, 4761-4767.

Bonasoni, P., Laj, P., Marinoni, A., Sprenger, M., Angelini, F., Arduini, J., Bonafe, U., Calzolari, F., Colombo, T., Decesari, S., Di Biagio, C., Di Sarra, A., Evangelisti, F., Duchi, R., Facchini, M., Fuzzi, S., Gobbi, G., Maione, M., Panday, A., Roccato, F., Sellegri, K., Venzac, H., Verza, G., Villani, P., Vuillermoz, E., Cristofanelli, P., 2010. Atmospheric brown clouds in the Himalayas: first two years of continuous observations at the Nepal Climate Observatory-Pyramid (5079 m). Atmos. Chem. Phys. 10, 7515-7531.

Cao, J., Wu, F., Chow, J., Lee, S., Li, Y., Chen, S., An, Z., Fung, K., Watson, J., Zhu, C., 2005. Characterization and source apportionment of atmospheric organic and elemental carbon during fall and winter of 2003 in Xi'an, China. Atmos. Chem. Phys. 5, 3127-3137.

Caricchia, A.M., Chiavarini, S., Pezza, M., 1999. Polycyclic aromatic hydrocarbons in the urban atmospheric particulate matter in the city of Naples (Italy). Atmos. Environ. 33, 3731-3738

Central Bureau of Statistics, 2006. Statistical Year Book of Nepal. Nepal Government.

Cheng, H., Deng, Z., Chakraborty, P., Liu, D., Zhang, R., Xu, Y., Luo, C., Zhang, G., Li, J., 2013. A comparison study of atmospheric polycyclic aromatic hydrocarbons in three Indian cities using PUF disk passive air samples. Atmos. Environ. 73, 16-21.

Crimmins, B., Dickerson, R., Doddridge, B., Baker, J., 2004. Particulate polycyclic aromatic hydrocarbons in the Atlantic and Indian Ocean atmospheres during the Indian Ocean Experiment and Aerosols 99: continental sources to the marine atmosphere. J. Geophys. Res. Atmos. 109, D05308.

Ding, X., Wang, X., Xie, Z., Xiang, C., Mai, B., Sun, L., Zheng, M., Sheng, G., Fu, J., Pöschl, U., 2007. Atmospheric polycyclic aromatic hydrocarbons observed over the North Pacific Ocean and the Arctic area: spatial distribution and source identification. Atmos. Environ. 41, 2061-2072.

Giri, D., Murthy, K., Adhikary, P., Khanal, S., 2006. Ambient air quality of Kathmandu Valley as reflected by atmospheric particulate matter concentrations $\left(\mathrm{PM}_{10}\right)$. Int. J. Environ. Sci. Technol. 3, 403-410.

Gong, P., Wang, X., Yao, T., 2011. Ambient distribution of particulate-and gas-phase n-alkanes and polycyclic aromatic hydrocarbons in the Tibetan Plateau. Environ. Earth Sci. 64, 1703-1711.

Gurung, A., Bell, M., 2013. The state of scientific evidence on air pollution and human health in Nepal. Environ. Res. 124, 54-64.

Harner, T., Bidleman, T., 1996. Measurements of octanol-air partition coefficients for polychlorinated biphenyls. J. Chem. Eng. Data 41, 895-899.

Harner, T., Bidleman, T., 1998. Octanol-air partition coefficient for describing particle/ gas partitioning of aromatic compounds in urban air. Environ. Sci. Technol. 32, 1497-1502.

ICIMOD, 2007. Kathmandu Valley environment outlook. International Centre for Integrated Mountain Development, Kathmandu, Nepal. 
Kando, A., Kaga, A., Imamura, K., Inoue, Y., Sugisawa, M., Shrestha, M., Sapkota, B., 2005. Investigation of air pollution concentration in Kathmandu Valley during winter season. J. Environ. Sci. 17, 1008-1013.

Kaur, S., Senthilkumar, K., Verma, V., Kumar, B., Kumar, S., Katnoria, J., Sharma, C., 2013. Preliminary analysis of polycyclic aromatic hydrocarbons in air particles $\left(\mathrm{PM}_{10}\right)$ in Amritsar, India: sources, apportionment, and possible risk implications to humans. Arch. Environ. Contam. Toxicol. 65, 382-395.

Kishida, M., Mio, C., Imamura, K., Kondo, A., Kaga, A., Shrestha, M., Takenaka, N., Maeda, Y. Sapkota, B., Fujimori, K., 2009. Temporal variation of atmospheric polycyclic aromatic hydrocarbon concentrations in $\mathrm{PM}_{10}$ from the Kathmandu Valley and their gasparticle concentrations in winter. Int. J. Environ. Anal. Chem. 89, 67-82.

Kulkarni, P., Venkataraman, C., 2000. Atmospheric polycyclic aromatic hydrocarbons in Mumbai, India. Atmos. Environ. 34, 2785-2790.

Liu, J., Li, J., Lin, T., Liu, D., Xu, Y., Chaemfa, C., Qi, S., Liu, F., Zhang, G., 2013. Diurnal and nocturnal variations of PAHs in the Lhasa atmosphere, Tibetan Plateau: implication for local sources and the impact of atmospheric degradation processing. Atmos. Res. 124, 34-43.

Ma, W., Sun, D., Shen, W., Yang, M., Qi, H., Liu, L., Shen, J., Li, Y., 2011. Atmospheric concentrations, sources and gas-particle partitioning of PAHs in Beijing after the 29th Olympic Games. Environ. Pollut. 159, 1794-1801.

Masih, A., Saini, R., Singhvi, R., Taneja, A., 2010. Concentrations, sources, and exposure profiles of polycyclic aromatic hydrocarbons (PAHs) in particulate matter $\left(\mathrm{PM}_{10}\right)$ in the north central part of India. Environ. Monit. Assess. 163, 421-431.

MEPC, 1996. Ministry of environmental protection of the People's Republic of China: ambient air quality standard (GB 3095-96). China Environmental Science Press, Beijing.

Ming, J., Cachier, H., Xiao, C., Qin, D., Kang, S., Hou, S., Xu, J., 2008. Black carbon record based on a shallow Himalayan ice core and its climatic implications. Atmos. Chem. Phys. 8, 1343-1352.

NEERI, 2006. Ambient air quality status for ten cities of India. Report (1991-2005). National Environmental Engineering Research Institute, Nagpur.

Nielsen, T., Jørgensen, H., Larsen, J., Poulsen, M., 1996. City air pollution of polycyclic aromatic hydrocarbons and other mutagens: occurrence, sources and health effects. Sci. Total Environ. 189, 41-49.

Nisbet, I., LaGoy, P., 1992. Toxic equivalency factors (TEFs) for polycyclic aromatic hydrocarbons (PAHs). Regul. Toxicol. Pharmacol. 16, 290-300.

Odabasi, M., Cetin, E., Sofuoglu, A., 2006. Determination of octanol-air partition coefficients and supercooled liquid vapor pressures of PAHs as a function of temperature: application to gas-particle partitioning in an urban atmosphere. Atmos. Environ. 40, 6615-6625.

Okuda, T., Naoi, D., Tenmoku, M., Tanaka, S., He, K., Ma, Y., Yang, F., Lei, Y., Jia, Y., Zhang, D., 2006. Polycyclic aromatic hydrocarbons (PAHs) in the aerosol in Beijing, China, measured by aminopropylsilane chemically-bonded stationary-phase column chromatography and HPLC/fluorescence detection. Chemosphere 65, 427-435.

Panday, A., Prinn, R., 2009. Diurnal cycle of air pollution in the Kathmandu Valley, Nepal: observations. J. Geophys. Res. Atmos. 114, D09305.

Park, S., Kim, J., Jeong, M., Song, B., 2011. Source identification of atmospheric polycyclic aromatic hydrocarbons in industrial complex using diagnostic ratios and multivariate factor analysis. Arch. Environ. Contam. Toxicol. 60, 576-589.

Rajput, N., Lakhani, A., 2009. Measurements of polycyclic aromatic hydrocarbons at an industrial site in India. Environ. Monit. Assess. 150, 273-284.

Rajput, N., Lakhani, A., 2010. Measurements of polycyclic aromatic hydrocarbons in an urban atmosphere of Agra, India. Atmosfera 23, 165-183.

Rajput, P., Sarin, M., Sharma, D., Singh, D., 2014. Atmospheric polycyclic aromatic hydrocarbons and isomer ratios as tracers of biomass burning emissions in Northern India. Environ. Sci. Pollut. Res. 21, 5724-5729.

Ram, K., Sarin, M., 2010. Spatio-temporal variability in atmospheric abundances of EC, OC and WSOC over Northern India. J. Aerosol Sci. 41, 88-98.

Ram, K., Sarin, M., Sudbeer, A., Rengarajan, R., 2012. Carbonaceous and secondary inorganic aerosols during wintertime fog and haze over urban sites in the IndoGangetic Plain. Aerosol Air Qual. Res. 12, 359-370.
Ramanathan, V., Ramana, M.V., Roberts, G., Kim, D., Corrigan, C., Chung, C., Winker, D. 2007. Warming trends in Asia amplified by brown cloud solar absorption. Nature 448, 575-578.

Rengarajan, R., Sarin, M., Sudheer, A., 2007. Carbonaceous and inorganic species in atmospheric aerosols during wintertime over urban and high-altitude sites in North India. J. Geophys. Res. Atmos. 112, D21307.

Sarkar, S., Khillare, P., 2013. Profile of PAHs in the inhalable particulate fraction: source apportionment and associated health risks in a tropical megacity. Environ. Monit Assess. 185, 1199-1213.

Shakya, K., Ziemba, L., Gruffin, R., 2010. Characteristics and sources of carbonaceous, ionic and isotopic species of wintertime atmospheric aerosols in Kathmandu Valley, Nepal. Aerosol Air Qual. Res. 10, 219-230.

Sharma, C., 1997. Urban air quality of Kathmandu Valley "Kingdom of Nepal". Atmos. Environ. 31, 2877-2883.

Sharma, H., Jain, V.K., Khan, Z.H., 2007. Characterization and source identification of polycyclic aromatic hydrocarbons (PAHs) in the urban environment of Delhi. Chemosphere 66, 302-310.

Shrestha, A., Aryal, R., 2011. Climate change in Nepal and its impact on Himalayan glaciers. Reg. Environ. Change 11, S65-S77.

Shrestha, R., Malla, S., 1996. Air pollution from energy use in a developing country city: the case of Kathmandu Valley, Nepal. Energy 21, 785-794.

Singh, D., Gadi, R., Mandal, T., Saud, T., Saxena, M., Sharma, S., 2013. Emissions estimates of PAH from biomass fuels used in rural sector of Indo-Gangetic Plains of India. Atmos. Environ. 68, 120-126.

Sinha, V., Kumar, V., Sarkar, C., 2014. Chemical composition of pre-monsoon air in the Indo-Gangetic Plain measured using a new air quality facility and PTR-MS: high surface ozone and strong influence of biomass burning. Atmos. Chem. Phys. 14 5921-5941.

Sitaras, I., Bakeas, E., Siskos, P., 2004. Gas/particle partitioning of seven volatile polycyclic aromatic hydrocarbons in a heavy traffic urban area. Sci. Total Environ. 327, 249-264.

Tham, Y., Takeda, K., Sakugawa, H., 2008. Polycyclic aromatic hydrocarbons (PAHs) associated with atmospheric particles in Higashi Hiroshima, Japan: Influence of meteorological conditions and seasonal variations. Atmos. Res. 88, 224-233.

Tripathee, L., Kang, S., Huang, J., Sharma, C., Sillanpaa, M., Guo, J., Paudyal, R., 2014. Concentrations of trace elements in wet deposition over the central Himalayas, Nepal. Atmos. Environ. 95, 231-238.

Vadrevu, K., Ellicott, E., Giglio, L., Badarinath, K., Vermote, E., Justice, C., Lau, W., 2012. Vegetation fires in the Himalayan region - aerosol load, black carbon emissions and smoke plume heights. Atmos. Environ. 47, 241-251.

Wang, W., Simonich, S., Wang, W., Giri, B., Zhao, J., Xue, M., Cao, J., Lu, X., Tao, S., 2011. Atmospheric polycyclic aromatic hydrocarbon concentrations and gas/particle partitioning at background, rural village and urban sites in the North China Plain. Atmos. Res. 99, 197-206.

Wang, Z., Na, G., Ma, X., Fang, X., Ge, L., Gao, H., Yao, Z., 2013. Occurrence and gas/particle partitioning of PAHs in the atmosphere from the North Pacific to the Arctic Ocean. Atmos. Environ. 77, 640-646.

Yunker, M., Macdonald, R., Vingarzan, R., Mitchell, R., Goyette, D., Sylvestre, S., 2002. PAHs in the Fraser River basin: a critical appraisal of PAH ratios as indicators of PAH source and composition. Org. Geochem. 33, 489-515.

Zhang, Y., Tao, S., 2009. Global atmospheric emission inventory of polycyclic aromatic hydrocarbons (PAHs) for 2004. Atmos. Environ. 43, 812-819.

Zhou, J., Wang, T., Huang, Y., Mao, T., Zhong, N., 2005. Seasonal variation and spatial distribution of polycyclic aromatic hydrocarbons in atmospheric $\mathrm{PM}_{10}$ of Beijing, People's Republic of China. Bull. Environ. Contam. Toxicol. 74, 660-666.

Zhu, Y., Yang, L., Yuan, Q., Yan, C., Dong, C., Meng, C., Sui, X., Yao, L., Yang, F., Lu, Y., Wang W., 2014. Airborne particulate polycyclic aromatic hydrocarbon (PAH) pollution in a background site in the North China Plain: concentration, size distribution, toxicity and sources. Sci. Total Environ. 466, 357-368. 